\title{
A comparison of clinical vs ultrasound determined synovitis in juvenile idiopathic arthritis (JIA) S Magni Manzoni*1, A Ravelli ${ }^{2}$, C Klersy ${ }^{1}, \mathrm{C} \mathrm{Visconti}^{1}$, S Lanni ${ }^{1}$, E Borali ${ }^{1}$, V Muratore $^{1}$, C Montecucco ${ }^{1}$ and O Epis ${ }^{1}$
}

Address: ${ }^{1}$ Dep. Pediatrics, Fondazione Policlinico IRCCS San Matteo, Pavia, Italy and ${ }^{2}$ Pediatria II, IRCCS G. Gaslini, Genova, Italy

* Corresponding author

from $15^{\text {th }}$ Paediatric Rheumatology European Society (PreS) Congress

London, UK. 14-17 September 2008

Published: 15 September 2008

Pediatric Rheumatology 2008, 6(Suppl I):PIOI doi:I0.II86/I546-0096-6-SI-PIOI

This abstract is available from: http://www.ped-rheum.com/content/6/SI/PIOI

(c) 2008 Manzoni et al; licensee BioMed Central Ltd.

\section{Purpose}

Studies in rheumatoid arthritis have shown higher prevalence of subclinical synovitis defined by US in respect to clinical examination. We investigated the relative sensitivity of clinical and sonographic assessment of synovitis in JIA.

\section{Methods}

In 34 patients, the clinician (SMM) assessed 52 joints and computed count of joints with swelling, pain/tenderness, restricted motion and active disease (AD). A global articular severity score (GASS) was obtained by grading symptoms in each joint (0-3 scale) and summing scores. Clinical assessments included physician's and parent's global ratings, functional ability and acute phase reactants. The sonographer (OE) scanned independently the same 52 joints for synovial hypertrophy (SI), synovial fluid (SF) and power Doppler (PD), each graded on a 03 scale. Agreement and correlations were assessed with Cohen's kappa and Spearman's correlation, respectively ( $>0.4=$ moderate agreement/correlation) .

\section{Results}

1768 joints were assessed. Knees, wrists, proximal interphalangeal joints and ankles were the most frequently affected joints, either clinically and on US. Table 1 shows kappa values for clinical vs. US assessments:

Disagreement was greater for intertarsal and metatarsophalangeal joints. US scores were moderately correlated with AD and GASS and poorly correlated with other clinical measures.

\section{Conclusion}

Swelling was the only clinical feature for which there was agreement with US. US revealed greater sensitivity than clinical examination in detecting synovitis in foot joints. These findings have important implications for application of US in clinical trials and predictive studies.

Table I: Kappa values for clinical vs. US assessments

\begin{tabular}{llll}
\hline & SI & SF & PD \\
\hline Swelling & 0.41 & 0.45 & 0.31 \\
Pain/tenderness & 0.29 & 0.27 & 0.35 \\
Restricted motion & 0.29 & 0.21 & 0.33 \\
\hline
\end{tabular}

